\title{
The social and economic impact of salmonellosis
}

\section{A report of a national survey in England and Wales of laboratory-confirmed salmonella infections}

\author{
P. N. SOCKETT ${ }^{1}$ AND J. A. ROBERTS ${ }^{2}$ \\ ${ }^{1}$ Public Health Laboratory Service, Communicable Disease Surveillance Centre, \\ Colindale Avenue, London NW9 5EQ \\ ${ }^{2}$ Health Services Research Unit, Department of Public Health and Policy, \\ The London School of Hygiene and Tropical Medicine, Keppel Street,
} London WC1E \%HT

(Accepted 9 April 1991)

\section{SUMMARY}

This study presents the findings of a national survey of 1482 cases of salmonellosis reported to Environmental Health Departments in England and Wales between August 1988 and March 1989. A questionnaire survey of ill individuals and the environmental health officers who investigated them sought information about costs which were imposed upon public health authorities, the health sector, individuals and their families and the costs to the wider economy in terms of lost production.

Costs of $£ 996339$ were identified. Over half (£507555) resulted from lost production due to sickness absence and more than a third (£392822) were costs to the public sector which resulted from health care and local authority investigation of cases. The remaining costs (£95962), although the smallest proportion of the total, indicated that salmonellosis can have a significant impact on affected individuals and their families.

\section{INTRODUCTION}

The social and economic impact of food-borne disease is considerable. It imposes costs upon the public sector, on industry, in particular the wholesale and retail food industry, and very importantly upon the infected person and their family. The illness may result in admission to hospital and, in a small proportion of cases, in death.

Public sector costs fall on the health sector which is directly involved in the care of patients and on public health and hospital laboratory and environmental health services responsible for investigating the illness. Costs to industry include the loss of productivity of those who are ill and those who may need to be off work to care for them and those who are prevented from working as a precautionary measure 
to stop the spread of infection. It also involves the loss of business, productivity and goodwill of industries or organizations implicated in an outbreak. Most importantly, it imposes costs upon the persons who are ill and those who care for them. These costs include those directly attributable to the illness, those associated with the lost opportunities to carry out normal daily activities and the pain, suffering and sometimes death which results from the illness.

As food-borne infection is preventable, these costs are potentially avoidable. It would, therefore, appear desirable to measure the costs of the illness in order to establish some measure of the savings that might accrue from preventive activity.

Despite the long history of the use of economic evaluation in the field of public health, for example, Calkin's use of Farr's work to calculate the impact of sanitary legislation in England at the end of the nineteenth century [1], there has been little interest, until recently, in using the economic calculus to examine the economic implications of food-borne illness or the benefits of its prevention.

Now, however, three factors have combined to direct attention towards the use of economic evaluation in this area. Firstly, the number of cases of salmonellosis recorded in England and Wales has risen from 4000-7000 a year in the mid 60's to over 23000 in $1988[2,3]$. Similar trends have been experienced in other developed countries. Manning, for example, reported an increase in salmonella infections recorded in the United States from 11 per 100000 in 1971 to more than 27 per 100000 in 1985 [4]. Although these increases may be partly due to increased ascertainment, the recent increase in England and Wales has resulted from a sharp rise in reporting of only one type of salmonella. Since doctors cannot selectively test for this salmonella the trend is probably real. Secondly, evidence is accumulating which suggests that the costs associated with salmonella infection and other food-borne illnesses are high $[5,6]$. Thirdly, the increased attention that has been placed on containing public expenditure and pressures on resources in these sectors has led to greater emphasis on the assessment of the efficacy and efficiency of public sector activities [7].

Many studies of the costs of food-borne disease, mainly salmonellosis, have examined the financial consequences of individual outbreaks. In such cases the number of persons affected is likely to be known fairly accurately and the resources employed in treatment and investigation of cases relatively easy to identify. The purpose of many of these types of study has been to identify and enumerate the categories of costs. However, some recent studies have attempted to relate costs to preventive activities. Such studies have assessed the benefits of primary prevention such as monitoring by health officers, pasteurization of milk and irradiation of poultry; and secondary prevention such as intervention to curtail outbreaks [8-11]. Some studies have attempted to extrapolate the costs of individual outbreaks to give estimates of the national impact of disease. This, however, is not a very reliable method of ascertaining national costs as the cost profiles of individual outbreaks can vary substantially and bold assumptions may have to be made about the quality of data, levels of under-reporting and the severity of the illness.

Studies to ascertain the national costs of salmonellosis have been undertaken in Canada and Germany; both studies relied upon assumptions about the sources of infection and the levels of infection in humans and animals based on surveys of 
expert opinion $[12,13]$. Although this approach may not necessarily lead to very accurate estimates they were compatible with the aims of the studies which were to provide a framework for looking at costs of illness and benefits of prevention. The main difference between the studies was the inclusion of costs relating to loss of life and the restriction of animal costs to those falling on the poultry industry in the Canadian study. The studies produced estimates of DM 108 million for costs of human infection and a further DM 132 million for costs of animal infections in the Federal Republic of Germany and $\$ 84$ million in Canada. These costs are considerable though still a small proportion of the respective health budgets of these countries.

There is very little detailed information available on the national costs of salmonellosis in England and Wales. Work derived from an earlier study of an outbreak led to further explorations to test the methodology for estimating the costs of infection [8]. A survey of 66 cases of salmonella infection which occurred in Birmingham in 1985 indicated that a questionnaire survey could provide detailed information on the costs of illness to the individual and the public sector [14]. Estimations of the full impact of the infection on industry would require a different methodology.

In response to the current increase in reporting, a survey to examine, in detail, the financial and social costs of salmonella infection was conducted in England and Wales between 1 August 1988 and 31 March 1989 which included periods of peak and low reporting.

\section{METHODS}

Estimates of the costs of salmonellosis were obtained by a questionnaire survey carried out in collaboration with Environmental Health Departments (EHDs). Letters inviting collaboration were sent to all Chief Officers of EHDs in England and Wales. Two hundred and nineteen agreed to collaborate in the study by participating in the survey and by distributing questionnaires. A case was defined as any person with laboratory-confirmed salmonella infection. Environmental Health Officers were requested to pass questionnaires together with a letter explaining the purpose of the study and a prepaid addressed return envelope to all cases which came to their notice during the study period, irrespective of the age of the person or the severity of their illness. This would normally be via either the notification of cases of food poisoning by medical practitioners to the Proper Officer for the District, or in the course of investigating notified cases or outbreaks. This approach was taken to minimize, as far as possible, any tendency to select particular groups of individuals.

The survey was in the form of a two part questionnaire linked by a common study number. Part A was designed to identify costs associated with the investigation of cases. It was addressed to the investigating Environmental Health Officer (EHO) who was asked to give details of the number of specimens submitted for laboratory testing from cases, contacts and foods or environment. Details of travel costs, administration and 'other' costs, and details of the time spent on the investigation by the various grades of staff were requested.

At the completion of the investigation by the EHO Part B was given to cases for completion. Part B was used to assess the use of health care services, including 
general practitioner and hospital services, and the impact on the economy due to sickness-related absence from work. The tangible and intangible costs of illness to the case and his or her family were also explored in detail in the questionnaire.

The questionnaires were designed to be self-coded except for occupation, family relationships and incidental expenditure which were centrally coded.

Based on the previous year, 1987, it was estimated that a sample equivalent to 5-10\% of reports expected during the study period would include the salmonella serotypes which normally account for $95 \%$ of reports to the Communicable Disease Surveillance Centre (CDSC). The number of questionnaires distributed to each Environmental Health Department was related to the proportion of the total population in England and Wales covered by that local authority district. Each department was asked to continue to distribute questionnaires until their quota was exhausted or the study ceased, whichever occurred first.

Non-responders were identified by receipt of a part A form from an EHO without a corresponding part B in the following 2 months. Such non-responders were sent a reminder letter together with a replacement part B questionnaire and a further short questionnaire asking for reasons for non-compliance.

Parts A and B of the questionnaire were checked for accuracy and consistency. The data were entered onto computer and verified by on-screen review ; finally the data sets were analysed for duplicate entries and coding inconsistencies.

\section{RESULTS}

The number of questionnaires distributed was taken to be the total of all Part A only, Part B only, and Parts A+B together returned. On this basis 1601 questionnaires were distributed. One hundred and nineteen were excluded because the onset of illness fell outside the study period, infection was due to another organism or the questionnaire was unreadable. The results presented are therefore based on the remaining 1482 questionnaires. Of these, 1229 included Part B questionnaires returned by infected individuals indicating a response rate from cases of $83 \%$. The date of onset of illness was available for $1266(85 \%)$ cases ; most, $87 \%$, were ill between July and December 1988 and the remaining $13 \%$ in the first 3 months of 1989.

The specific salmonella serotype identified was recorded for 745 cases. Most were Salmonella enteritidis (61\%), S. typhimurium (21\%) or S. virchow (4\%) and all other serotypes recorded accounted for the remaining $15 \%$ of cases (Table 1 ). This distribution matched closely the distribution of salmonella serotypes reported to the CDSC during the same period (PHLS Communicable Disease Surveillance Centre, unpublished). The major proportion of cases (875 cases, $59 \%$ ) were sporadic, that is they had no known association with other cases. A further 423 $(29 \%)$ were part of a single household (family outbreaks) or were associated with outbreaks following meals at restaurants, receptions etc. (general outbreaks). No information was given for the remaining $184(12 \%)$. Twenty per cent (303) cases became ill or were infected whilst on holiday outside the British Isles. Most had visited either European countries $(59 \%)$, in particular Spain, or North Africa $(29 \%)$. This distribution probably reflected the popularity of Mediterranean 
Table 1. Comparison of distribution of serotypes in study sample with reports to CDSC during study period from laboratories in England and Wales

Number and proportion (\%) of identifications

\begin{tabular}{lcc}
\cline { 2 - 3 } Serotype & Study sample & Reports to CDSC \\
S. enteritidis & $451(60 \cdot 5)$ & $11999(58 \cdot 9)$ \\
S. typhimurium & $156(20 \cdot 9)$ & $4373(21 \cdot 4)$ \\
S. virchow & $30(4 \cdot 0)$ & $812(4 \cdot 0)$ \\
Other serotypes & $108(14 \cdot 5)$ & $3219(15 \cdot 8)$ \\
$\quad$ Total & 745 & 20403
\end{tabular}

Table 2. Occupational groups of 1223 cases

$\begin{array}{lrccr}\text { Occupation } & \text { Male } & \text { Female } & \text { Not stated } & \text { Total } \\ \text { Pre-school child } & 104 & 93 & 1 & 198 \\ \text { Schoolchild } & 65 & 74 & - & 139 \\ \text { Student } & 9 & 10 & - & 19 \\ \text { Full-time employed } & 311 & 202 & - & 513 \\ \text { Part-time employed } & 6 & 146 & - & 152 \\ \text { Housewife } & - & 95 & - & 95 \\ \text { Retired } & 45 & 39 & - & 84 \\ \text { Unemployed } & 11 & 12 & - & 23 \\ \quad \text { Total } & 551 & 671 & 1 & 1223\end{array}$

resorts with British holidaymakers and the possibility that persons with a recent history of travel abroad are more likely to be asked to submit a specimen for laboratory examination.

There were more females $(55 \%)$ than males $(45 \%)$ in the sample due entirely to an excess of adult females aged 15 and over. In general the age distribution of the sample was similar to the age distribution of all salmonella cases reported to CDSC in 1989 (the first year for which this information was available); although cases aged under 1 year and 65 years or over were under represented. However, the study sample showed significant differences when compared with the age distribution of the population of England and Wales, showing a marked excess of children aged under 5 years whereas the elderly (aged $>65$ years) were considerably under represented. The reasons for this are unclear, but may indicate a greater likelihood that doctors will submit a specimen for laboratory tests when the patient is a young child. The severity of illness recorded ranged from symptomless excretion and mild diarrhoea to severe illness and death.

Details of occupation were given for 1223 cases (Table 2). The sample included 665 adults in full or part-time employment. A further 23 persons of employable age were classified as unemployed. Of the 95 women described as housewives 15 were aged over 60 years (actual age not stated for 2 cases). School children and students accounted for 158 cases, and 198 cases were pre-school children.

\section{Public health costs of investigation and testing}

The costs of investigation were $£ 157162$ (Table 3) and were based on answers provided by EHOs to part A of the questionnaire. Costs included investigation of the source of infection and payments for exclusion from work, if necessary, of 
those who were ill. Staff costs were calculated using information about the grade of staff employed, time spent on the investigation and their position on the salary scale, adjusted to take into account all costs of employment. Costs of laboratory testing were taken from PHLS estimates made in 1982 expressed as 1988/89 prices. These included staff time to conduct tests and costs of consumables [15].

No attempt was made to apportion capital costs of these institutions which are involved in multiple and varied activities. To apportion costs of the public health infrastructure would have involved a different and very extensive inquiry.

\section{Costs to the health sector}

\section{Hospital costs}

Two hundred and twenty-seven (18.5\%) respondents were admitted to hospital for an average of 6.4 days. The costs of a day in hospital were derived from Hospital Costing Returns for 1988 updated using the price index provided by the Department of Health (DoH) (Economic Advisors Office, DoH, personal communication). Costs per day of an acute medical admission in 1988/89 were estimated as $£ 119$. This rate was used to estimate the cost per case and the total cost to the health sector for the patients in the sample (Table 3).

Many patients were treated at Accident and Emergency departments (AED) or attended hospital Out-Patient departments (OPD) as a consequence of their illness. The costs of a first and subsequent attendance at each department was estimated, using the Hospital Costing Returns adjusted for 1988/89 prices. These amounted to $£ 4289$ and $£ 16444$ for AED and OPDs respectively.

Transport to and from hospital was sometimes made by ambulance and costs of ambulance journeys were estimated with the help of the York Ambulance Service. Differentiation was made between the cost of an emergency ambulance admission and discharge home by 'bus' ambulance (York Ambulance Service, personal communication) [16].

Some patients were accompanied to hospital by carers, some of whom stayed in hospital with child patients. It has not, as yet, been possible to estimate the cost to the hospital sector of those who stayed. It is possible that any costs were compensated for by saving nursing time, surveillance or attending to patients; but this is not clear.

\section{General practice and community services}

The major impact of salmonellosis on the general practice i.e. the ambulatory care sector of the health service was estimated. A total of 866 patients visited their doctors on average $2 \cdot 2$ times and 587 patients were visited at home by their doctor on average $2 \cdot 1$ times. Because of the way in which general practitioners (GPs) are paid for their services in the UK (capitation fee for registered patients, practice allowance and fee for service), it might be argued that there is no opportunity cost associated with consultation with GPs. However, it could also be argued that GPs are fully-employed, busy people and that the time taken up by an additional patient who has salmonellosis precludes the doctors from doing something else almost as valuable, i.e. the opportunity cost is not zero. We have adopted the latter view and in consultation with the DoH and British Medical Association 
Table 3. Public sector costs

$\begin{array}{lr} & \text { Total }(£) \\ \text { Public health costs } & \\ \text { Local authority (EHD) } & 85632.69 \\ \text { Laboratory testing } & 71529.40 \\ & \mathbf{1 5 7 1 6 2 . 0 9} \\ \text { Medical (NHS) treatment costs } & \\ \text { General practice } & 31367.35 \\ \text { Hospital services } & 193642.25 \\ \text { Ambulance service } & 2959.50 \\ \text { Prescriptions (net cost to NHS) } & 7690.51 \\ & \mathbf{2 3 5 6 5 9 . 6 1} \\ \text { Total } & 392821.70\end{array}$

(BMA) have derived figures which approximate to the cost of a consultation (£7) or visit by GP (£14.45) at $1988 / 89$ prices. These gave an estimated total cost for the sample of $£ 31367$ (Table 3 ).

The patients may need the service of other staff from social or community services, but as the illness is sudden and acute, it is unlikely that these services are used, except in areas where visits by nurses instead of doctors are common. Cohen (Aberdeen) found high use in a rural area in Scotland but Sockett in a study in Birmingham found no use $[10,14]$. We have no details of the use of these services for our sample.

\section{Costs of medicines}

The cost of treating cases of salmonellosis depends not only on what is the most effective treatment but also on the expectations of doctors and patients about the care required. On average 1.33 prescriptions per case were provided; the costs of these prescriptions were estimated using DoH cost data for 1988/89 ( $£ 6.33$ per case) adjusted to take into account the proportion paid by patients for these prescriptions. The net cost to the NHS was £7691 and the cost per case was £6.26.

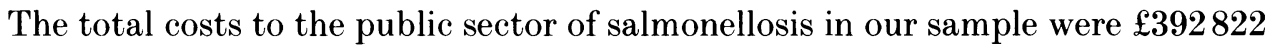
a cost per case of $£ 298$. Sixty per cent of these costs fell upon the health sector for the treatment of cases and the remaining $40 \%$ were for public health activities by local authorities.

\section{Costs to families and the economy}

The costs to patients and families

The guiding principle used to assess the costs to patients was to estimate how much it would cost to place them in the position in which they would have been had the infection not occurred. It was not assumed that these costs represented the value patients would place on avoiding the illness. The costs of the illness do however represent some minimum value of benefits. It could be argued that details of costs and a profile of the physical impact of the illness should be provided as background information in studies which attempt to ascertain benefits using the 'willingness to pay' approach. Some of the costs fall directly upon those infected and other costs fall on family members and friends. 
Table 4. Family costs of illness

Total $(\mathfrak{E})$

$\begin{array}{lr}\text { Costs of GP consultations } & \\ \text { Travel (cases) } & 1892.90 \\ \text { Travel (accompanying persons) } & 38.48 \\ \text { Prescribed medicine (patient contributions) } & 2735.20 \\ & \mathbf{4 6 6 6 . 5 8} \\ \text { Costs of hospitalization } & \\ \text { Travel (cases) } & 2029.04 \\ \text { Travel (visitors) } & \mathbf{4 2 8 5 . 8 9} \\ \text { Trousseau } & 2630.75 \\ \text { Expenditure in OPD } & 78.29 \\ & \mathbf{9 0 2 3 . 9 7} \\ \text { Other family costs } & \\ \text { Additional expenditure } & \mathbf{1 8 0 2 0 . 6 5} \\ \text { Cnexpected losses due to illness } & 9204.05 \\ \text { Expenditure/losses from illness acquired abroad } & \mathbf{5 5 0 4 6 . 7 8} \\ & \mathbf{8 2 2 7 1 . 4 8} \\ \text { Total } & \mathbf{9 5 9 6 2 . 0 3}\end{array}$

\section{Costs of obtaining general practitioner services}

The direct costs of receiving treatment from general practitioners is shown in Table 4. Forty-one per cent of these costs were associated with travel by patients and others and $59 \%$ to those patients who were not exempt from prescription charges. The proportion exempt from charges in the sample was much less than that for the population as a whole who contribute to slightly less than $20 \%$ of items prescribed. This may be explained by the age structure and composition of our population which was largely composed of people under 65 years of age who were otherwise healthy.

\section{Costs of hospitalization}

Transport of patients and their visitors accounted for over two thirds of the costs of hospitalization (Table 4). A further third, however, was spent on incidental expenses associated with hospital stay. Some of these expenses, which people incur in order to present themselves appropriately in encounters with the health sector, have been described by Abel-Smith as the Trousseau effect (B. Abel-Smith, personal communication). These costs, whilst small, can be a burden on the budgets of families.

\section{Other costs of the illness}

Table 4 shows the costs which were specified by patients as having been incurred as a result of the illness; these included expenditure needed to cope with the illness. Over one third of these expenses related to medicines and medical care, and hygiene and communications accounted for a further $22 \%$ of the costs. These costs were largely predictable consequences of the illness. Individuals, however, faced a wide range of unpredictable costs which resulted from illness. Unforeseen expenditure and losses from cancelled arrangements included a large proportion of costs arising from spoilt holidays. It was assumed that people value a day's 
Table 5. Lost production

\begin{tabular}{|c|c|c|c|}
\hline \multirow{3}{*}{ Full-time } & & Days off work & Cost $(\mathfrak{E})$ \\
\hline & Men & 3552 & 174971.52 \\
\hline & Women & 3199 & 108030.23 \\
\hline \multirow{3}{*}{ Part-time } & : Men & 39 & 1921.14 \\
\hline & Women & 2547 & 86012.19 \\
\hline & & 9337 & 370935.08 \\
\hline \multirow[t]{4}{*}{ Carers } & $\operatorname{Men}(\mathrm{P} / \mathrm{FT})$ & 542 & 26698.92 \\
\hline & Women & 936 & 31608.72 \\
\hline & Not known & 15 & 656.25 \\
\hline & & 1493 & 58963.89 \\
\hline \multicolumn{2}{|c|}{$\begin{array}{l}\text { Total* } \\
\text { including labour costs }\end{array}$} & 10830 & $\begin{array}{l}429898.97 \\
507554.98\end{array}$ \\
\hline
\end{tabular}

* Gender specific (male rate : 49·26; female rate $33 \cdot 77$ ); Non-gender specific (rate : 43.75), total $£ 559400.82$ including labour costs.

holiday at least as much as the price they have paid for it. Some unforeseen expenses, including a lost honeymoon, represent some challenges for the economic calculus which we have not attempted to assess.

\section{Lost productivity}

By far the largest component ( $51 \%$ ) of the costs of salmonellosis was represented by lost production (Table 5). There is some debate about the extent to which absence from work affects productivity and in some instances the work will be made up either by 'slack' in the system or by imposing extra work on other members of staff. Conversely, absence of a key individual may cause losses disproportionate to that person's apparent contribution. It was impossible to ascertain in our study the precise effects on productivity and the method chosen seems to be the least biased approximation to productivity loss. Some analysts take the position that there is no productivity loss if there is any unemployment in the system on the assumption that replacement staff can be taken on from the pool of unemployed. One could argue, however, that unemployment is a matter for the macro management of the economy and evaluation of health provision should not be unduly affected by the ebbs and flows of cyclical unemployment. In the case of salmonella infection presence or absence of unemployment is largely irrelevant as the periods of absence, in most cases, will be short and the costs of seeking alternative employees would be prohibitive.

The questionnaire requested information about the time off work by patients and those who cared for them as a result of their illness. This lost production was calculated as far as possible using estimated average earnings for men and women for the period of the study. These were adjusted for labour costs to assess the estimated value of the production lost. This figure was also adjusted to remove the differential payments made to men and women which raised the estimated losses to half a million pounds. We have not estimated 'time costs' which are not associated with loss of work. We recognize that these costs are important and merit a more detailed analysis. 
Table 6. Summary of costs

\begin{tabular}{|c|c|c|}
\hline & $\begin{array}{l}\text { Total cost } \\
\quad(\mathfrak{f})\end{array}$ & $\begin{array}{l}\text { Cost per } \\
\text { case }(\mathfrak{f})\end{array}$ \\
\hline \multicolumn{3}{|l|}{ Public sector costs } \\
\hline Local authority investigations* & 85632.69 & 57.78 \\
\hline \multirow[t]{2}{*}{ Laboratory costs* } & 71529.40 & 48.27 \\
\hline & $\overline{157162.09}$ & $\overline{106.05}$ \\
\hline General practice costs & 31367.35 & 25.52 \\
\hline Hospital services (inc. ambulance) & 196601.75 & 159.97 \\
\hline \multirow[t]{3}{*}{ Prescribed medicines } & 7690.51 & 6.26 \\
\hline & $\overline{235659.61}$ & $\underline{\underline{191.75}}$ \\
\hline & $\overline{\mathbf{3 9 2 8 2 1 . 7 0}}$ & $\overline{297.80}$ \\
\hline \multicolumn{3}{|l|}{ Families and economy } \\
\hline \multirow{2}{*}{$\begin{aligned} \text { Costs of treatment: } & \text { GP } \\
& \text { Hos }\end{aligned}$} & 4666.58 & 3.80 \\
\hline & 9023.97 & 7.34 \\
\hline \multirow[t]{2}{*}{ Other costs of illness } & 82271.48 & 66.94 \\
\hline & 95962.03 & 78.08 \\
\hline \multirow[t]{2}{*}{ Loss production (gender specific) } & $\underline{507554.98}$ & $\underline{412.98}$ \\
\hline & $\overline{603517.01}$ & $\overline{491.06}$ \\
\hline Total & 996338.71 & 788.86 \\
\hline
\end{tabular}

\section{Summary of costs}

The costs derived from the questionnaire are summarized in Table 6 . The costs were converted into costs per case by dividing local authority and laboratory costs by the relevant sample size, 1482 . The costs per case for the remaining categories was based on the total of 1229 respondents. The cost per case was estimated as $£ 789$ and the total costs associated with the sample of patients studied was $£ 996339$.

The range in costs-per-case was however very wide and was particularly sensitive to the costs of hospitalization and to lost production. Thus, for cases admitted to hospital, treatment costs ranged from $£ 119$ for a patient admitted for 1 day to over $£ 4000$ for a patient in hospital for 34 days. This had a knock-on effect resulting in corresponding increases in travel costs to families and friends visiting the patient. Similarly for patients off paid employment, the costs of lost production ranged widely depending on the number of days off.

\section{DISCUSSION}

The costs estimated in this study suggest that human salmonellosis is expensive to the public sector, industry and families. Based on the 23000 reported cases alone in 1988 public sector costs would have been about $£ 6.8$ million whilst costs to industry from lost production would have been $£ 9.5$ million. These are under estimates of the true costs since they take no account of costs of unreported cases, or estimates of costs of general discomfort of the illness or lives lost or indeed the longer term sequelae of infection [17].

This study was concerned solely with laboratory-confirmed cases and, in terms of the distribution of serotypes reported and the age distribution of cases, the 
sample accurately represented laboratory-reported cases of salmonellosis recorded by CDSC. It could be argued that the cases ascertained in this study, because they had come to the notice of EHDs, would represent more severely ill persons. Although this was probably true, to some extent, the severity of illness in the sample ranged widely. Many more cases do not come to the attention of the authorities but still impose considerable disruption and discomfort on those affected and cause loss of productivity and increased use of general practitioner services. Adding such costs would substantially increase the costs of salmonellosis to the economy but as they would include many less severe cases they would reduce the average cost per case.

The costs identified in this study represented only a part of the impact of salmonellosis on patients and their families. Salmonellosis is an unpleasant condition and whilst no attempt was made to value pain and suffering in this study we attempted to compile a profile of the condition and its impact on the patient using a series of questions about the number of symptoms experienced, their severity and the number of days spent in each state. It is intended that this work will be used subsequently as a basis for a health status measure for acute episodes of illness.

Three people included in our sample died whilst infected with salmonellae including two people who were in poor health. This is slightly less than we might predict for the sample size [15]. Questionnaires were returned by the families of two of these cases. Valuing life is a difficult and contentious area. In previous work using an approach also adopted by Cohen and colleagues [10] we provided estimates based on implicit value of life derived from decisions in the public sector, values based on the human capital approach and values based on the willingness to pay estimations. Even using the lower estimates, including the value of lives lost substantially increases the average cost per case of salmonellosis from $£ 789$ to $£ 1200-1500$. Willingness to pay values would raise the cost per case to approximately $£ 6000$.

This study has not estimated the costs of salmonellosis on firms which might be involved in an outbreak. Documented cases reported in other studies indicate the enormous sums which may be involved in such outbreaks which, in some instances, have resulted in withdrawal of products and closure of factories $[5,6,9,18-20]$. Costs of treatment and containment to the agricultural industry as indicated by studies in Germany and Canada are also high $[12,13]$. The estimates we give therefore need to be seen in the context of a potentially expensive but essentially preventable illness which so far as national reporting in the UK is concerned, has increased considerably in recent years. Reports suggest that similar trends are being recorded in many European countries and North America [21, 22].

It is therefore important to document as fully as possible the costs of illness. This will provide a basis for the economic analysis of preventive strategies. This may take the form of an analysis of the costs and benefits derived from preventive activities per se and may contribute to the decisions about choice of preventive strategies by the food industry at different points in food production.

Salmonellosis is only one of many food-borne infections some of which are generally less severe but recorded in high numbers [3]. Others are reported in low 
numbers but may be very severe with a comparatively high associated mortality. It is hoped that this study will provide a model for the study of these and other acute illnesses, and it is being adapted currently for major studies of gastrointestinal infections.

\section{ACKNOWLEDGEMENTS}

We would like to thank Dr N.S. Galbraith and the late Professor Patrick Hamilton for their encouragement in this study. We wish to express our sincere gratitude to the staff of the many Environmental Health Departments in England and Wales who collaborated in this study.

\section{REFERENCES}

1. Calkins GN. Some results of sanitary legislation in England since 1875. Publ Am Stat Assoc 1891 : $297-303$.

2. Galbraith NS, Barrett NJ, Sockett PN. The changing pattern of foodborne disease in England and Wales. Public Health 1987; 101 : 319-28.

3. Galbraith NS. The epidemiology of foodborne disease in England and Wales in the 1980's. Outlook Agricult 1990; 19: 95-101.

4. Manning EL. Danger lurks in your supermarket meat cases. J Am Vet Med Assoc 1988; 192: 414-97.

5. Todd ECD. Economic loss from foodborne disease outbreaks associated with food service establishments. J Food Protect 1985; 48: 169-80.

6. Mann JD, Lathrop GD, Bannerman JA. Economic impact of a botulism outbreak. JAMA $1983 ; 249$ : $1299-301$.

7. Roberts JA. The national health service in the UK : from myths to markets. Health Policy Planning $1989 ; 4: 62-71$.

8. Roberts JA, Sockett PN, Gill ON. Economic impact of a nationwide outbreak of salmonellosis : cost-benefit of early intervention. BMJ $1989 ; 298$ : 1277-30.

9. Levy BS. The economic impact of a foodborne salmonellosis outbreak. JAMA 1974; 230 : $1281-2$.

10. Cohen DR, Porter IA, Reid TMS, Sharp JCM, Forbes GI, Paterson GM. A cost benefit study of milkborne salmonellosis. J Hyg $1983 ; 91$ : 17-23.

11. Yule BF, Forbes GI, Macleod AF, Sharp JCM. The costs and benefits of preventing poultryborne salmonellosis in Scotland by irradiation. Aberdeen: Health Services Research Unit. University of Aberdeen, 1986. (Discussion paper 05/86.)

12. Krug W, Rehm N. Nutzen-kosten-analyse der Salmonellose bekampfung. Schriftenreihe des Bundesministers für Jugend, Familie und Gesundheit. Stuttgart: W Kohlhammer, 1983.

13. Curtin L. Economic study of salmonella poisoning and control measures in Canada. Working paper 11/84. Food Markets Analysis Division, Marketing and Economics Branch, Agriculture Canada, 1984.

14. Sockett PN, Stanwell-Smith R. Cost analysis of the use of health-care services by sporadic cases and family outbreaks of Salmonella typhimurium and campylobacter infection. In: Proceedings of the 2nd World Congress on foodborne infections and intoxications. Berlin: WHO 2: 1036-9.

15. Roberts JA, Sockett PN, Gill ON. Costs benefit analysis of controlling a national outbreak of Salmonella napoli: exploring a method. London School of Hygiene and Tropical Medicine, Health Services Research Unit, 1990.

16. National ambulance service survey 1988-89. District Finance Department, York Health Authority, 1990.

17. Archer DL. Diarrhoeal episodes and diarrhoeal disease: acute disease with chronic implications. J Food Project 1984; 47 : 322-8.

18. Todd ECD. Economic loss resulting from microbial contamination of food. In: Proceedings of the second national conference for food protection. Washington DC: US Food and Drug Administration, $1984 ; 151-66$. 
19. Sockett PN, Roberts JA. Social and economic implications of foodborne infection. In: Goldring O, ed. Salmonella and listeria, implications for food safety. EAG Scientific Ltd, 1989: 185-209.

20. Todd ECD. Economic loss from foodborne disease and non-illness related recalls because of mishandling by food processors. J Food Protect; 48: 621-33.

21. Todd E. Epidemiology of foodborne illness: North Africa. Lancet $1990 ; 336: 788-93$.

22. Gerigk K. Foodborne disease in Europe: present situation and future developments of the WHO surveillance programme. 2nd UNDP Steering Committee Meeting on Food Safety ICP/FOS 029/6. Budapest: WHO, 1990. 